\title{
Электронная микроскопия жильного кварца месторождения Фенькина-Лампи (Карелия)
}

\author{
Светова Е.Н., Бубнова Т.П. \\ Институт геологии КарНЦ РАН, Петрозаводск, ensvetova@igkrc.ru
}

\begin{abstract}
Аннотация. Представлены результаты электронно-микроскопического исследования молочно-белого жильного кварца месторождения Фенькина-Лампи. Проанализирована исходная кварцевая крупка и кварцевые концентраты различной степени очистки. Операции обогащения кварцевой крупки фракции $-0.63+0.1$ мм включали электромагнитную сепарацию, сверхвысокочастотную и ультразвуковую обработку, кислотное выщелачивание в $\mathrm{HCl}\left(10 \%\right.$ p-p, $100^{\circ} \mathrm{C}, 1$ час) и $\mathrm{HF}_{\text {конц }}\left(100^{\circ} \mathrm{C}, 1\right.$ час). Выявлены основные особенности удаления микроминеральных и газово-жидких включений в технологическом процессе.
\end{abstract}

Ключевые слова: жильный кварц, обогащение, электронная микроскопия, Фенькина-Лампи.

\section{Electron microscopy of vein quartz of the Fenkina-Lampi deposit (Karelia)}

\author{
Svetova E.N., Bubnova T.P. \\ Institute of Geology, Karelian Research Centre, RAS, Petrozavodsk, ensvetova@igkrc.ru
}

\begin{abstract}
The results of electron microscopy studies of milky white vein quartz of the Fenkina-Lampi deposit are presented. The initial quartz grains $(-0.63+0.1 \mathrm{~mm})$ and quartz concentrates of various treatment degree are analyzed. The processing included electromagnetic separation, microwave and ultrasonic treatment, $\mathrm{HCl}$ and $\mathrm{HF}$ leaching. The main features of the removal of mineral and fluid inclusions in the process are revealed.
\end{abstract}

Key words: vein quartz, processing technology, electron microscopy, Fenkina-Lampi.

Важным критерием при качественно-технологической оценке кварцевого сырья является содержание элементов-примесей, входящих в кварц в виде микроминеральных и газово-жидких включений (ГЖВ), а также локализующихся в его кристаллической структуре. Для получения высококачественных кварцевых концентратов технология обогащения предусматривает стандартные методы удаления минеральных примесей и газово-жидких включений, с которыми связана основная часть элементов-примесей: магнитную сепарацию, флотацию, термическую и кислотную обработку кварцевой крупки. Разрабатываются и применяются нестандартные подходы: воздействие сверхвысокочастотных (СВЧ) электромагнитных колебаний, плазмоочистка (Насыров, 2009; Скамницкая и др., 2013; Гришин и др., 2013). Химические анализы подтверждают эффективное снижение содержания примесей после таких операций, однако полного их удаления не происходит. В кварце остаются структурные примеси, удаление которых пока недостижимо, а также часть неструктурных примесей, связанных с твердыми и жидкими микрочастицами. Количество остающихся включений в кварце варьирует в зависимости от их состава, формы нахождения, от особенностей строения самого кварца.

С целью контроля чистоты кварцевой крупки и выявления особенностей удаления минеральных и ГЖВ при разных операциях очистки нами проведено сравнительное электронномикроскопическое изучение исходной и обогащенной крупки жильного кварца месторождения Фенькина-Лампи. Как показывают ранее выполненные минералого-технологические исследования, среди твердых минеральных включений для данного кварца наиболее характерны хлорит и кальцит, в меньшем количестве присутствуют слюды, полевой шпат, оксиды и гидроксиды железа, единичные микровключения рутила, апатита, циркона. Минеральные примеси приурочены в основном к трещинам и границам кварцевых зерен, что благоприятно для их удаления при технологической обработке. Серьезной проблемой при обогащении слабопрозрачного кварца является присутствие в нем большого количества ГЖВ, влияющих на чистоту кварцевых концентратов (Скамницкая, Данилевская, 2009; Скамницкая и др., 2019). С учетом данной особенности в операции очистки 


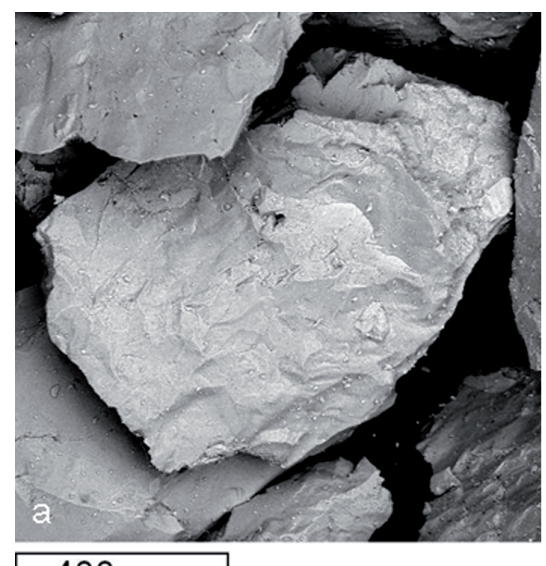

400мкm

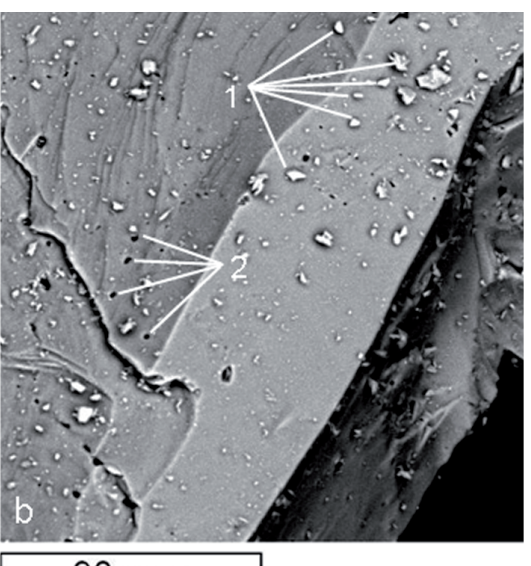

$90 \mathrm{M \kappa m}$

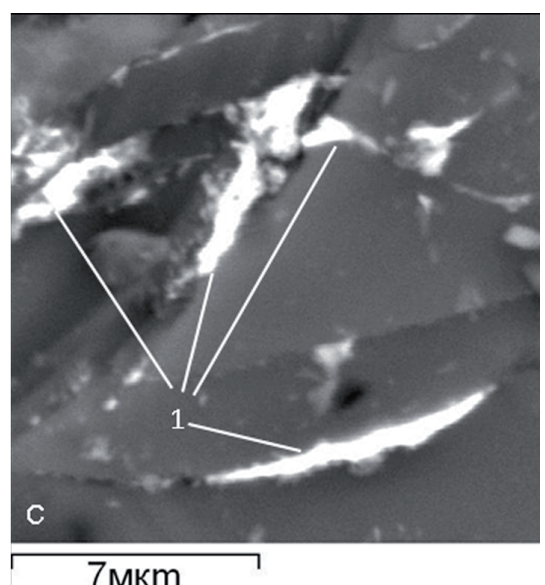

7мкm

Рис. 1. Электроно-микроскопические изображения зерен исходной кварцевой крупки. $\mathrm{a}$ - типичное кварцевое зерно; $\mathrm{b}$ - поверхность скола с осажденной кварцевой крошкой (1) и порами от вскрывшихся ГЖВ (2); с - включения магнетита по микротрещинам в кварце.

Fig. 1. Electron microscopy images of untreated quartz grains.

a - typical quartz grain; $b$ - grain surface with precipitated quartz chips (1) and pores from released fluid inclusion (2); $\mathrm{c}-$ iron oxide (1) inclusions.

включена СВЧ обработка кварцевой крупки. Суть СВЧ воздействия состоит в эффекте декрепитации (вскрытии ГЖВ), возникающем при нагревании жидкости, входящей в состав ГЖВ. В результате резкого возрастания давления происходит разрыв и растрескивание окружающего зерна с выходом содержащейся жидкости.

Технологические эксперименты выполнены на лабораторном оборудовании отдела минерального сырья ИГ КарНЦ РАН под руководством Л. С. Скамницкой. Обогащение кварцевой крупки фракции $-0.63+0.1$ мм проводилось в следующей очередности: 1 . Электромагнитная сепарация с последующим скрабированием. 2. СВЧ обработка (900 Вт, 2.45 ГГц, 10 мин). 3. Ультразвуковая дезинтеграция в водной среде (ультразвуковой диспергатор УЗДН-2Т, 22 Гц, 3 мин). 4. Выщелачивание в $\mathrm{HCl}\left(10 \%\right.$ p-p, $100^{\circ} \mathrm{C}, 1$ час). 5. Выщелачивание в $\mathrm{HF}_{\text {конц }}\left(100^{\circ} \mathrm{C}, 1\right.$ час). После каждой операции производилась промывка крупки в дистиллированной воде.

Анализ напыленной углеродом кварцевой крупки разной степени очистки выполнен на сканирующем электронном микроскопе VEGA II LSH (Tescan), оснащенном энергодисперсионным анализатором INCA Energy 350 в Аналитическом центре ИГ КарНЦ РАН. При разных увеличениях исследована крупка исходного кварца; концентрат, полученный в результате электромагнитной сепарации и СВЧ-обработки; концентраты, полученные после кислотного выщелачивания в $\mathrm{HCl}$ и $\mathrm{HF}$.

Согласно результатам исследования, крупка исходного крупнозернистого молочно-белого кварца представлена относительно изометричными зернами с гладкими гранями или с типичными для кварца раковистыми сколами (рис. 1 а). На поверхности зерен наблюдается осажденная кварцевая пыль, образовавшейся в процессе дробления кварца. Местами зерна несут следы от вскрывшихся вдоль сколов газово-жидких включений (рис.1 b). Среди минеральных примесей часто наблюдаются железооксидные фазы, локализованные по микротрещинкам (рис. 1 с) или образующие пленки на поверхности зерен. Реже отмечаются включения плагиоклаза, галита и кальцита.

Результатом электромагнитной сепарации и скрабирования кварцевой крупки в водной среде стало удаление техногенных магнитных частиц и осажденной пылевидной фракции кварца, связанных с процессом дробления.

СВЧ-обработка кварцевой крупки приводит к расколу некоторой части зерен, в основном наиболее крупных. Очагами разрушений, по-видимому, являются исходные поверхностные микротрещины, границы блоков, линейные дислокации и другие концентраторы напряжений. В результате такого воздействия в общей массе зерен образуется большое количество тонкопластинчатых кварцевых частиц (рис. 2), которые концентрируются в процессе обработки на поверхности воды в 
виде пленки. На сколах частиц наблюдается большое количество вскрытых вакуолей газово-жидких включений (рис. 2 b). Вместе с тем, отмечаются твердофазные включения размером 5-15 мкм, отвечающие по составу кальциту, ангидриту, плагиоклазу (рис. 2 c). Вероятно, данные микроминеральные включения были вскрыты вследствие раскалывания кварцевых зерен и частично осаждены на их поверхности. Для удаления с поверхности кварца осажденных микровключений далее выполнена ультразвуковая дезинтеграция кварцевой крупки в дистиллированной воде.

Обработанная соляной кислотой кварцевая крупка представлена преимущественно нетронутыми травлением зернами с гладкой или тонковолокнистой поверхностью сколов (рис. 3 a). Небольшая часть зерен характеризуется локальными участками поверхности со следами активного растворения (рис. 3 b, с). В единичных случаях отмечаются железооксидные микровключения (рис. 3 b).

Воздействие плавиковой кислоты на кварцевую крупку приводит к формированию огромного количества борозд травления, образующих часто сетку дефект-каналов на поверхности зерен (рис. 3 d). Местами, в результате активного растворения наблюдаются тончайшие кварцевые иголки размером менее 1 мкм (рис. 3 е). Растворение кварца сопровождается высвобождением микроминеральных включений, локализованных в близповерхностных участках зерен. В ряде случаев отмечаются оставшиеся после травления включения оксидов железа, хлоридов натрия и калия (рис. 3 е). Можно предположить, что такие включения были скрыты за тончайшими кварцевыми стенками, препятствовавшими их высвобождению при контакте с кислотой, а попав в вакуум при напылении электропроводящим слоем, прорвали их. Выделения хлоридов натрия и калия могли также образоваться в результате высыхания солевых растворов из вскрывшихся ГЖВ.

Таким образом, электронно-микроскопические исследования позволяют качественно контролировать чистоту кварцевой крупки в процессе технологических операций и выявлять поверхностные особенности зерен кварца, обусловленные глубоким обогащением. Энергетическое воздействие полем СВЧ приводит к декрепитации большого количества ГЖВ, о чем свидетельствуют множественные следы от вскрытых ГЖВ в виде пор характерного размера и морфологии. Кислотное травление сопровождается активным растворением близповерхностной части кварцевых зерен и высвобождением микроминеральных включений из этих областей. Очевидно, что растворение кварца происходит вдоль залеченных трещин, содержащих эти включения, около микротрещин и других напряженных участков. Однако полного удаления твердофазных примесей не происходит. Количественная оценка эффективности удаления элементов примесей и газово-жидких включений в кварцевых концентратах будет выполнена в предстоящей работе.
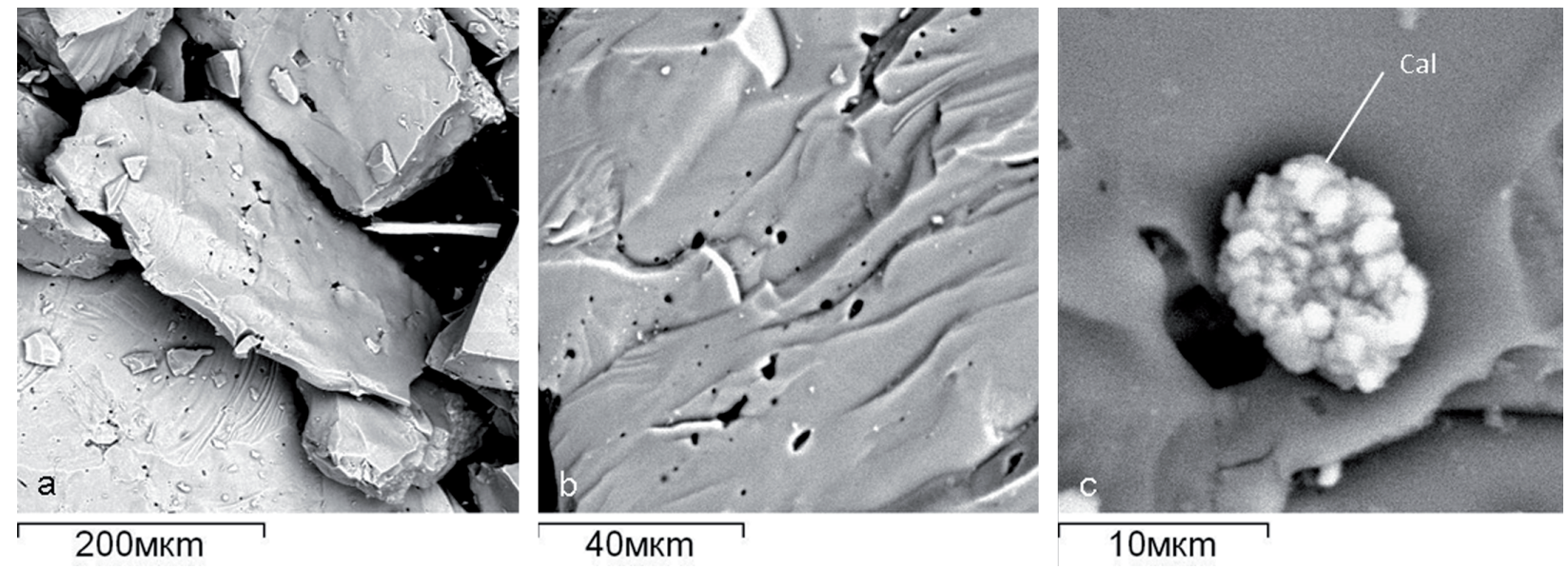

Рис. 2. Электронно-микроскопические изображения зерен СВЧ-обработанной кварцевой крупки. a - тонкопластинчатая частица кварца; b - деталь поверхности скола со следами от вскрывшихся ГЖВ; с - микронеоднородное включение кальцита (Cal).

Fig. 2. Electron microscopy images of quartz grains treated by microwave.

$\mathrm{a}$ - thin-platy quartz grain, $\mathrm{b}$ - pores of released fluid inclusions; $\mathrm{c}$ - microinhomogeneous calcite (Cal) inclusion. 

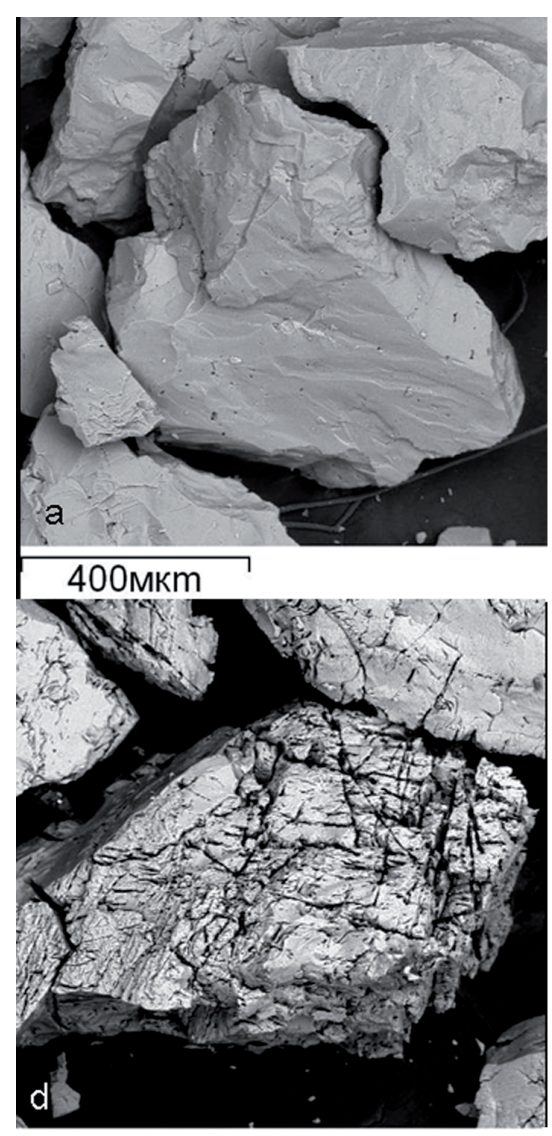

Зо0мкт

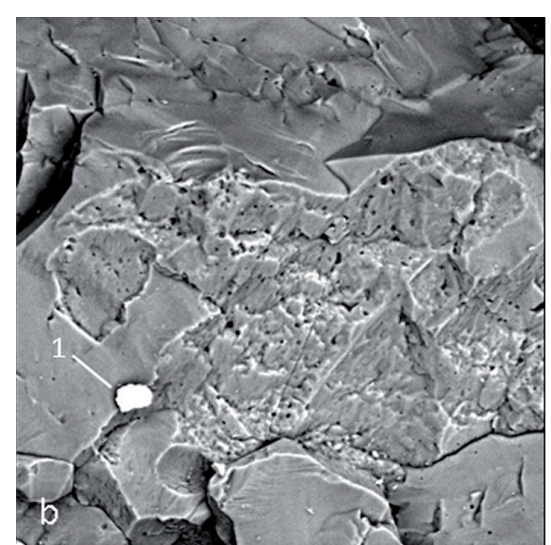

$100 \mathrm{mKm}$

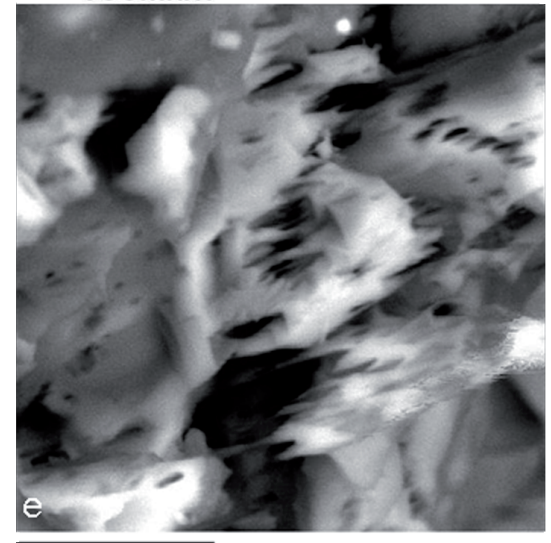

$10 \mathrm{mkm}$
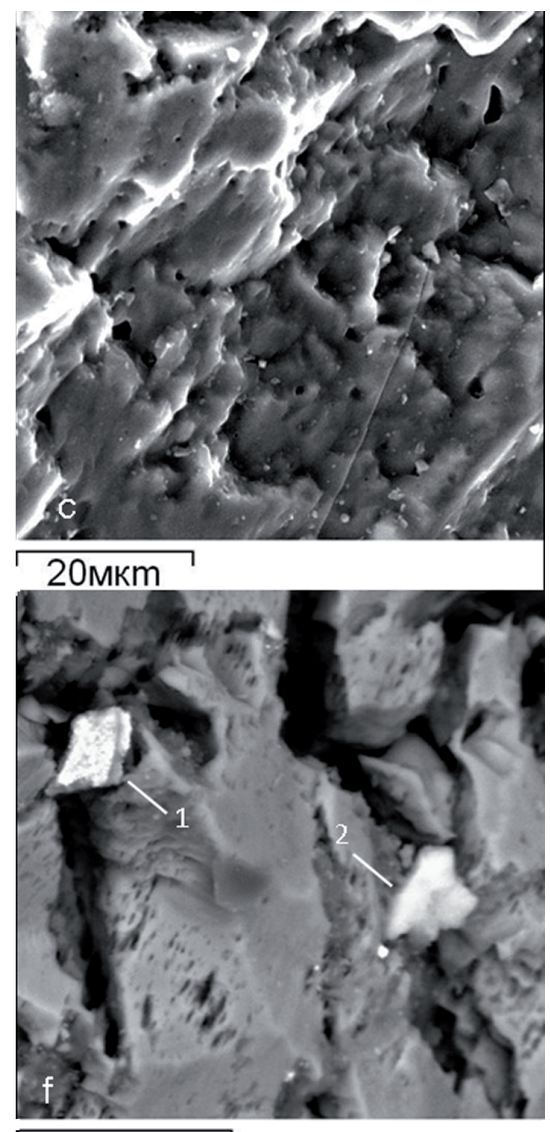

Зомкm

Рис. 3. Электроно-микроскопические изображения зерен обработанной кислотами кварцевой крупки (верхний ряд - после обработки $\mathrm{HCl}$, нижний - после НF): a - нетронутое травлением зерно кварца; $\mathrm{b}$ - растворенная область поверхности зерна с примесным железооксидным включением (1); с - форма растворения кварца; $\mathrm{d}$ - сеть дефект-каналов на зерне кварца; е - форма растворения кварца; f - минеральные включения оксида железа и галита.

Fig. 3. Electron microscopic images of acid-treated quartz grains (upper line - after leaching in $\mathrm{HCl}$, lower line - after leaching in HF): $a$ - quartz grain untouched by acid leaching; $b$ - dissolved part of grain surface with iron oxide inclusion (1); c - detailed image of quartz dissolution; $\mathrm{d}$ - quartz grain with defect channels network; $\mathrm{e}$ - form of quartz dissolution; $\mathrm{f}$ - inclusions of iron oxide (1) and halite (2).

Работа выполнена в рамках государственного задания Института геологии КарНЦ РАН.

\section{Литература}

1. Гришин Ю.М., Козлов Н.П., Кулагин А.Ю. Экспериментальное исследование финишного этапа обогащения кварца в плазменных потоках // Инженерный журнал: наука и инновации. 2013. Bып. 10. URL: http://engjournal.ru/ catalog/ machin/ plasma/1027.html.

2. Насыров Р.Ш. СВЧ-декрепитация газожидкостных включений в кварцевых зернах // Обогащение руд. 2009. № 2. С. 26-27.

3. Скамницкая Л.С., Данилевская Л.А. Выбор методов обогащения кварца на основе закономерностей распределения и форм нахождения в нем примесей (на примере участков Меломайс и Фенькина-Лампи) // Новые методы технологической минералогии при оценке руд металлов и промышленных минералов. Сборник научных статей по материалам российского семинара по технологической минералогии. Петрозаводск: КарНЦ РАН. 2009. С. 83-94.

4. Скамницкая Л.С., Данилевская Л.А., Раков Л.Т., Дубинчук В.Т. Способ обогащения природного кварцевого сырья. Патент №2483024 РФ. 2013. Бюл. №15. 9 с.

5. Скамницкая Л.С., Светова Е.Н., Шанина С.Н. Влияние газово-жидких включений на качество жильного кварца // Обогащение руд. 2019. №2. C. 20-26. DOI: 10.17580/or.2019.02.04. 